@Sayadi L, Faezi ST, Hasanpour M, Alahmadi SJ

\title{
The Relationship of Lifestyle with Disease Activity among Patients with Systemic Lupus Erythematosus: A Descriptive-Correlational Study
}

\section{Leila Sayadi1 (D), Seyedeh Tahereh Faezi² (D), Marzieh Hasanpour ${ }^{3}$ (D), Sofia Jami Alahmadi³}

${ }^{1}$ Nursing and Midwifery Care Research Centre, School of Nursing \& Midwifery, Tehran University of Medical Sciences, Tehran, Iran, ${ }^{2}$ Rheumatology Research Centre, Tehran University of Medical Sciences, Tehran, Iran, ${ }^{3}$ School of Nursing \& Midwifery, Tehran University of Medical Sciences, Tehran, Iran

\section{ABSTRACT}

Objective: The objective of this study was to evaluate the relationship of lifestyle with disease activity among patients with systemic lupus erythematosus. Methods: This cross-sectional descriptivecorrelational study was conducted in 2019 on 209 patients with systemic lupus erythematosus. Data were collected using a demographic and clinical characteristics questionnaire, the HealthPromoting Lifestyle Profile II, and the systemic lupus erythematosus disease activity Index. The data were analysed through the mixed model and the logistic regression analyses. Results: In total, $67.5 \%$ of participants had active disease. The mean score of lifestyle was $2.49 \pm 0.30$ and the lowest and the highest lifestyle dimensional mean scores were respectively related to the physical activity and the health responsibility dimensions $(1.55 \pm 0.60$ and 3.25 \pm 0.45$)$. The analysis showed that each one point increase in the mean score of lifestyle was associated with 0.79 point decrease in the odds of disease activity $(P=0.006)$. Moreover, disease activity had significant positive relationship with body mass index $(P=0.015)$. Conclusion: Interventions for promoting lifestyle among these patients and improving healthcare providers' knowledge about Systemic lupus erythematosus and lifestyle modification are recommended to reduce disease activity.

Mediterr J Rheumatol 2021;32(2):124-33

https://doi.org/10.31138/mir.32.2.124

Article Submitted: 4 Oct 2020; Revised Form: 5 Nov 2020; Article Accepted: 15 Dec 2020; Available Online: 30 Jun 2021

Keywords: Systemic lupus erythematosus, lifestyle, disease activity

\author{
Corresponding Author: \\ Sofia Jami Alahmadi \\ School of Nursing \& Midwifery \\ Tehran University of Medical Sciences, \\ Tehran, Iran \\ Nosrat St. Tohid Sq. \\ Tehran, Iran 141973317 \\ Tel.: +9821610 54325 \\ Fax: +982166904252 \\ E-mail: s.jami_735@hotmail.com
}

\author{
ABBREVIATIONS \\ $\mathrm{Cl}$ : Confidence interval \\ DA: Disease Activity \\ HPLPII: Health-Promoting Lifestyle Profile II \\ SLE: Systemic lupus erythematosus \\ SLEDAl: Systemic Lupus Erythematosus Disease Activity Index
}

\section{INTRODUCTION}

Systemic lupus erythematosus (SLE) is a chronic multisystemic autoimmune disease. Its pathogenesis is unknown, although genetic predisposition and environmental fac- 
tors such as solar ultraviolet radiation, infections, and medications may trigger it. In SLE, antibodies react to normal body cells instead of foreign antigens, resulting in the formation of immune complexes which deposit in different body tissues and cause tissue injury. ${ }^{1}$ The incidence of SLE is 1-10 cases per 100000 person-years, and its prevalence is 20-200 cases per 100000.2,3 A study in Iran showed that one per 2500 Iranians is afflicted by SLE. ${ }^{4,5}$ SLE is prevalent in ages between 14 and 44 years, and $90 \%$ of patients with SLE are women. ${ }^{2,6}$

SLE is associated with many different symptoms and consequences. Its symptoms include skin rashes, photophobia, joint swelling and pain, weakness, fatigue, and kidney disorders. ${ }^{2}$ Multisystemic involvement causes patients different problems, imposes financial strains on them due to treatment costs and disability, and makes them dependent and unable to fulfil their care-related needs. ${ }^{7}$ SLE considerably restricts daily activities, particularly at the time of pain recurrence, and causes difficulties in employment, interpersonal relationships, and social roles. ${ }^{8}$ Repeated relapses and progression of SLE considerably affect the musculoskeletal system, skin, kidneys, heart, lungs, and central nervous system, ${ }^{9}$ resulting in frequent hospitalisations. SLE treatment includes immunosuppressive agents, which are in turn associated with many different side effects and complications. ${ }^{10}$ SLE-related mortality is related to disease activation, infections, nephritis, acute renal failure, thrombosis secondary to antiphospholipid syndrome, carditis, pneumonia, pulmonary hypertension, cardiovascular complications, atherosclerosis, stroke, and myocardial infarction. These factors increase SLE-related mortality 2 or 5 times greater than the mortality rate in the general population. 9,11

SLE is associated with courses of relapse and remission. In other words, it may relapse due to many different factors, even in case of complete recovery with treatments. SLE relapse and activation are associated with a course of active inflammation throughout the body. ${ }^{12}$ Therefore, reducing disease activity (DA) is a main outcome in SLE treatment and care. ${ }^{13}$ SLE severity and DA are affected by a wide range of factors, including climate, genetic factors, race, ethnicity, and sociocultural status. ${ }^{5,14-16}$ Lifestyle is also a significant factor that contributes to SLE relapse and DA.

Lifestyle is defined as individuals' beliefs about and their strategies for health-related behaviours, including nutrition, physical activity, health responsibility, stress management, interpersonal relationships, and spiritual growth. ${ }^{16,17}$ Lifestyle reflects attitudes, values, and self-image, and is reflected in daily activities, such as eating, rest and exercise, relationships, thinking, planning, driving, sleep, and work. It is greatly affected by culture, environment, personal characteristics, personal and social relationships, ${ }^{18}$ geographical environment, and ethnicity. ${ }^{5,14-16}$ Lifestyle greatly affects general health, and has a significant relationship with most health problems including chronic diseases. ${ }^{19}$

As SLE is a chronic disease with lifelong symptoms, lifelong need for treatment and care, frequent courses of relapse and remission, and considerable effects on different body systems, afflicted patients need to have lifelong adherence to a healthy lifestyle. ${ }^{15,16,20-23}$ These patients need to engage in healthy lifestyle behaviours, such as regular physical activity, relationships with family members and close friends, tobacco abstinence, and a diet high in polyunsaturated fatty acids. ${ }^{16}$ Nonetheless, previous studies reported poor lifestyle among these patients. For instance, a study in Iran showed that patients with SLE did not have a healthy dietary regimen. ${ }^{14}$ Another study in Taiwan reported that patients with SLE had poor lifestyle, $72 \%$ of them had low sleep quality, and 20\%$32 \%$ of them suffered from severe depression and anxiety. ${ }^{24}$ Similarly, a study in Egypt showed that more than $75 \%$ of patients with SLE were overweight or obese. ${ }^{25}$ Lifestyle has potential effects on DA among patients with SLE. A study in Sweden showed that patients with SLE who had healthier lifestyle experienced lower levels of fatigue. ${ }^{15}$ Another study in Egypt reported that SLE DA had significant relationship with body mass index. ${ }^{25}$ A systematic review also showed that DA in SLE had a significant positive relationship with tobacco use. ${ }^{16}$

Although there are wide differences among different geographical areas respecting lifestyle behaviours and SLE severity and DA, ${ }^{26}$ limited studies have so far addressed the relationship of SLE DA with lifestyle in Iran. Most studies on patients with SLE in Iran were on SLE epidemiology, characteristics, ${ }^{4,5}$ diagnosis, treatment, and associated outcomes ${ }^{27}$ such as depression, anxiety, and quality of life. ${ }^{8}$ This study sought to address this gap. The aim of the study was to evaluate the relationship of lifestyle with DA among patients with SLE.

\section{MATERIALS AND METHODS \\ Design}

This cross-sectional descriptive-correlational study was conducted from April to December 2019.

\section{Setting and participants}

Study setting was the rheumatology clinic of a largescale public teaching hospital affiliated to Tehran University of Medical Sciences, Tehran, Iran. Study population consisted of all patients who referred to the study setting. Participants were 209 patients with SLE who were recruited through consecutive sampling. Inclusion criteria were age over eighteen years, ability to read and write in Persian, definite diagnosis of SLE by a rheumatologist, history of referring to the study setting for receiving SLE treatment and care for at least one year, and consent for participation. Participants were excluded if they refrained from answering the study instruments. With a correlation 
coefficient of 0.22 between lifestyle and quality of life, ${ }^{24}$ a type I error of 0.05 , and a type II error of 0.10 , sample size was estimated to be 209 (Figure 1).

\section{Instruments}

Data were collected using a demographic and clinical characteristics questionnaire, the Health-Promoting Lifestyle Profile II (HPLPII), and systemic lupus erythematosus disease activity index (SLEDAI). The items of the demographic and clinical characteristics questionnaire were on age, gender, marital status, number of children, educational level, occupation, place of residence, living arrangement, positive family history of SLE, cigarette smoking, alcohol consumption, drug abuse, duration of affliction by SLE, body mass index, and history of hypertension and pulmonary, haematologic, renal, and hepatic disorders. HPLPII, developed based on Pender's Health Promotion Model, contains 52 items scored 1 ("Never"), 2

$$
n=\left[\frac{\left(z_{1-\alpha / 2}+z_{1-\beta}\right)}{0.5 \times \ln [(1+r) /(1-r)]}\right]^{2}
$$

Figure 1. Sample size calculation.

("Sometimes"), 3 ("Often"), or 4 ("Routinely"). The six dimensions of HPLPII are nutrition (nine items), physical activity (eight items), health responsibility (nine items), stress management (eight items), interpersonal relationships (nine items), and spiritual growth (nine items). The total score of HPLPII and each of the dimensions is obtained through the sum of the scores that ranged from 52 to 208. However, the use of the mean rather than the sum of the scales is recommended. So, the total score of each dimension is calculated through dividing its sum score by the number of its items and the total score of

Table 1. Participants' demographic characteristics.

Participants' demographic characteristics

Mean \pm SD or $\mathbf{N}(\%)$

Age (Years) $41.32 \pm 12.15$

\begin{tabular}{|c|c|c|}
\hline \multirow{2}{*}{ Gender } & Male & $17(8.1)$ \\
\hline & Female & $192(91.9)$ \\
\hline \multirow{2}{*}{ Marital status } & Single & $53(27)$ \\
\hline & Married & $156(74)$ \\
\hline \multirow{3}{*}{ Educational level } & Below diploma & $90(43.1)$ \\
\hline & Diploma & $73(34.9)$ \\
\hline & University & $46(22)$ \\
\hline \multirow{2}{*}{ Cigarette smoking } & Yes & $7(3.3)$ \\
\hline & No & $202(96.7)$ \\
\hline \multicolumn{2}{|c|}{ Duration of cigarette smoking (Years) } & $18 \pm 10.59$ \\
\hline \multicolumn{2}{|c|}{ Number of cigars smoked daily } & $12.62 \pm 11.56$ \\
\hline \multirow{2}{*}{ Alcohol consumption } & Yes & $3(1.4)$ \\
\hline & No & $206(98.6)$ \\
\hline \multicolumn{2}{|c|}{ Duration of alcohol consumption (Years) } & $14.6 \pm 13.61$ \\
\hline \multirow{2}{*}{ Positive family history of SLE } & Yes & $13(6.2)$ \\
\hline & No & $196(93.8)$ \\
\hline \multicolumn{2}{|c|}{ Duration of affliction by SLE(Month) } & $137.8 \pm 111.4$ \\
\hline \multicolumn{2}{|c|}{ Body mass index } & $25.69 \pm 4.64$ \\
\hline \multirow{6}{*}{ Body mass index } & $<18.5$ (Underweight) & $7(3.3)$ \\
\hline & 18.5-24.9 (Normal weight) & $99(47.4)$ \\
\hline & 25.0-29.9 (Overweight) & $65(31.1)$ \\
\hline & 30.0-34.9 (Class I obesity) & $27(12.9)$ \\
\hline & 35.0-39.9 (Class II obesity) & $10(4.8)$ \\
\hline & $\geq 40$ (Class III obesity) & $1(0.5)$ \\
\hline
\end{tabular}


Table 2. The mean scores of HPLPII and SLEDAI.

\begin{tabular}{lllcc}
\hline Variables & & Mean \pm SD & 95\% Cl & Range \\
\hline \multirow{7}{*}{ HPLPII } & Total & $2.49 \pm 0.30$ & & $1.83-3.56$ \\
& Physical activity & $1.55 \pm 0.60$ & $1.46-1.63$ & $1.00-3.63$ \\
& Stress management & $1.99 \pm 0.43$ & $1.93-2.05$ & $1.13-3.75$ \\
& Health responsibility & $3.25 \pm 0.45$ & $3.19-3.31$ & $1.67-3.89$ \\
& Nutrition & $2.87 \pm 0.40$ & $2.81-2.92$ & $1.67-3.67$ \\
& Spiritual growth & $2.35 \pm 0.50$ & $2.29-2.42$ & $1.11-4.00$ \\
& Interpersonal relationships & $2.77 \pm 0.47$ & $2.71-2.84$ & $1.44-3.78$ \\
\hline SLEDAI & & & $0-20$ \\
\hline
\end{tabular}

$\mathrm{Cl}$ : Confidence interval.

HPLPII is calculated through dividing the sum score of all 52 items by 52 . Therefore, the score of HPLPII and its dimensions can range from 1 to $4.28-30$ Previous studies reported acceptable reliability and validity for the Persian and Turkish HPLPII. ${ }^{17,28,31}$ Studies in Iran reported that the Cronbach's alpha values of the dimensions of the Persian HPLPII were 0.79-0.87. ${ }^{17,28}$ In the present study, HPLPII validity was approved by 13 experts in nursing and rheumatology and its Cronbach's alpha was 0.71.

SLEDAI is an appropriate checklist for DA assessment among patients with SLE. ${ }^{32}$ It consists of 24 items, namely 16 items on clinical findings, and eight items on laboratory findings. ${ }^{32}$ The first eight items are on seizure, psychosis, organic brain syndrome, visual disturbance, lupus headache, cranial nerve disorder, cerebrovascular accident, and vasculitis, and are scored either 0 ("No") or 8 ("Yes"). The next six items are on arthritis, myositis, urinary cast, haematuria, proteinuria, and pyuria and are scored 0 ("No") or 4 ("Yes"). The next seven items are on skin rash, alopecia, oral or nasal mucosal ulcers, pleurisy, pericarditis, low complement, and increased DNA binding and are scored either 0 ("No") or 2 ("Yes"). The last three items are on fever, thrombocytopenia, and leukopenia and are scored either 0 ("No") or 1 ("Yes"). The possible total score of SLEDAI is $0-105$. Scores less than 6 show inactive SLE, while scores 6 and greater show active SLE. This checklist assesses DA in the past 10 days and is sensitive to DA variations in the past 30 days. ${ }^{22,33}$

\section{Procedure}

Participants completed the demographic and clinical characteristics questionnaire and HPLPII through the self-report method. Some participants felt tired at completing these instruments and hence, one of authors (SJ) completed these instruments for them through the interview method. Moreover, the original version of the SLEDAl checklist was completed for participants by rheumatologists based on participants' clinical and laboratory characteristics.

\section{Statistical analysis}

The STATA16 (StataCorp, College Station, Texas, USA) was used for data analysis. Categorical variables were described through the absolute and the relative frequency measures, while numerical variables were described through the mean and standard deviation measures. The normality of the data was assessed and confirmed through the skewness and the kurtosis measures. The mean scores of lifestyle dimensions were compared with each other through the mixed model analysis with compound symmetry covariance structure. Difference of demographic characteristics with HPLPII were measured by Pearson, Independent sample T test, and ANOVA. The univariate and the multivariate logistic regression analyses were employed to evaluate the relationship of the dichotomous variable of DA (categorised as active or inactive) with the scores of lifestyle, its dimensions, and its personal characteristics. In univariate logistic regression analysis, each independent variable was entered into an independent model. For multivariate logistic regression analysis, hierarchical modelling was used, in which the scores of lifestyle and its dimensions were entered into a single model in the first step, and then demographic and clinical characteristics were entered into the same model in the next step. Odds ratio with 95\% confidence interval $(95 \% \mathrm{Cl})$ was calculated as effect size. The goodness of fit of the final logistic regression model was tested through the Hosmer-Lemeshow test. Moreover, the accuracy, sensitivity, and specificity measures were calculated for the model. The level of significance in all analyses was set at less than 0.05 .

\section{RESULTS}

The means of participants' age and body mass index were $41.32 \pm 12.15$ years and $25.69 \pm 4.64$, respectively. Most of participants were female (91.9\%), more than two-fifths of them had below-diploma education (43.1\%), and around half of them were overweight or obese (49.3\%). The length of suffering from SLE was 137.8 \pm 111.4 months, on average (Table 1). 
Table 3. The difference of total mean scores of HPLPII with Participants' demographic characteristics.

\begin{tabular}{|c|c|c|c|}
\hline \multirow{2}{*}{\multicolumn{2}{|c|}{ Participants' demographic characteristics }} & \multicolumn{2}{|c|}{ Total mean scores of HPLPII } \\
\hline & & Mean \pm SD & P Value \\
\hline \multicolumn{2}{|l|}{ Age $\left(\right.$ Years) ${ }^{*}$} & & 0.182 \\
\hline \multirow{2}{*}{ Gender $^{\dagger}$} & Male & $2.45 \pm 0.28$ & \multirow{2}{*}{0.659} \\
\hline & Female & $2.49 \pm 0.30$ & \\
\hline \multirow{2}{*}{ Marital status ${ }^{\dagger}$} & Single & $2.54 \pm 0.30$ & \multirow{2}{*}{0.097} \\
\hline & Married & $2.46 \pm 0.29$ & \\
\hline \multirow{3}{*}{ Educational level $\left.\right|^{\ddagger}$} & Below diploma & $2.43 \pm 0.25$ & \multirow{3}{*}{0.009} \\
\hline & Diploma & $2.49 \pm 0.32$ & \\
\hline & University & $2.60 \pm 0.32$ & \\
\hline \multirow{2}{*}{ Cigarette smoking ${ }^{\dagger}$} & Yes & $2.31 \pm 0.38$ & \multirow{2}{*}{0.177} \\
\hline & No & $2.49 \pm 0.29$ & \\
\hline \multicolumn{2}{|c|}{ Duration of cigarette smoking (Years) ${ }^{*}$} & & 0.15 \\
\hline \multicolumn{2}{|c|}{ Number of cigars smoked daily* } & & \multirow{3}{*}{$\begin{array}{l}0.221 \\
0.889\end{array}$} \\
\hline \multirow{2}{*}{ Alcohol consumption ${ }^{\dagger}$} & Yes & $2.49 \pm 0.30$ & \\
\hline & No & $2.49 \pm 0.30$ & \\
\hline \multicolumn{2}{|c|}{ Duration of alcohol consumption (Years) ${ }^{*}$} & & \multirow{3}{*}{$\begin{array}{l}0.958 \\
0.939\end{array}$} \\
\hline \multirow{2}{*}{\multicolumn{2}{|c|}{ Positive family history of $\mathrm{SLE}^{\dagger} \begin{array}{l}\text { Yes } \\
\text { No }\end{array}$}} & $2.47 \pm 0.38$ & \\
\hline & & $2.49 \pm 0.29$ & \\
\hline \multicolumn{2}{|c|}{ Duration of affliction by SLE(Month) ${ }^{*}$} & & 0.496 \\
\hline \multicolumn{2}{|c|}{ Body mass index } & & 0.994 \\
\hline
\end{tabular}

"Pearson correlation; ' Independent sample T test; ${ }^{\text {ANNOVA. }}$

SLE was active among $67.5 \%$ of participants (141 out of 209 participants). The mean score of HPLPII was $2.49 \pm 0.30$ (in the possible range of 1-4) (Table 2). The results of the mixed model analysis with compound symmetry covariance structure showed that there was at least one significant difference between the dimensions of lifestyle. The results of the Sidak post hoc test revealed that except for the difference between the nutrition and the interpersonal relationships dimensions $(P=0.139)$, all other pairwise differences between lifestyle dimensions were statistically significant $(P<0.05)$. The lowest and the highest dimensional mean scores were related to the physical activity $(1.55 \pm 0.60)$ and the health responsibility (3.25 \pm 0.45 ) dimensions (Table 2).

There was a significant difference between educational level and HPLPII, so that patients with academic level had better HPLPII score comparing to below diploma $(P=0.02)$. However, there was not any differences between diploma with academic $(\mathrm{P}=0.053)$ and below diploma ( $P=0.212)$ (Table 3).

The results of the univariate logistic regression analysis showed that the mean scores of lifestyle and its stress management and spiritual growth dimensions had sig- nificant negative relationships with SLE DA, so that each one point increase in the mean scores of lifestyle and its stress management and spiritual growth dimensions was associated with respectively $0.76,0.63$, and 0.57 point decrease in the mean score of SLE DA. Moreover, the results of the same analysis revealed that the mean score of body mass index had significant positive relationship with SLE DA, so that the odds of DA were seven times greater among those who were overweight or had firstor second-class obesity (Table 4).

The Hosmer-Lemeshow test revealed the goodness of fit of the final hierarchical logistic regression model $(P$ $>0.05)$. The accuracy, sensitivity, and specificity values of the model for predicting the active state of SLE were $76 \%, 94 \%$, and $38 \%$, respectively. The results of the multivariate logistic regression analysis illustrated a significant negative relationship between the mean score of lifestyle and SLE DA, so that each one point increase in the mean score of lifestyle was associated with 0.79 point decrease in the odds of SLE DA. Moreover, SLE DA had significant positive relationship with body mass index, so that the odds of SLE DA among those who were overweight, had first-class obesity, and had sec- 
Table 4. The results of the univariate logistic regression analysis to evaluate the relationship of SLEDAI with HPLPII and personal characteristics.

\begin{tabular}{|c|c|c|c|c|}
\hline \multicolumn{2}{|l|}{ Independent variables } & Odds Ratio & $95 \% \mathrm{Cl}$ & $P$ value \\
\hline \multirow{7}{*}{ Lifestyle } & Total & 0.241 & $0.088-0.660$ & 0.006 \\
\hline & Physical Activity & 0.873 & $0.544-1.403$ & 0.576 \\
\hline & Stress management & 0.370 & $0.186-0.740$ & 0.005 \\
\hline & Health responsibility & 0.536 & $0.265-1.083$ & 0.082 \\
\hline & Nutrition & 0.501 & $0.232-1.079$ & 0.077 \\
\hline & Spiritual growth & 0.426 & $0.232-0.780$ & 0.006 \\
\hline & Interpersonal relationships & 0.654 & $0.349-1.226$ & 0.186 \\
\hline \multicolumn{2}{|l|}{ Age } & 1.011 & $0.987,1.036$ & 0.363 \\
\hline \multirow{2}{*}{ Gender } & Male* & 1.000 & & \\
\hline & Female & 0.255 & $0.057-1.147$ & 0.075 \\
\hline \multirow{3}{*}{ Educational level } & Below diploma* & 1.000 & & \\
\hline & Diploma & 1.260 & $0.639-2.482$ & 0.504 \\
\hline & University & 0.676 & $0.324-1.409$ & 0.296 \\
\hline \multirow{2}{*}{ Cigarette smoking } & Yes $^{\star}$ & 1.000 & & \\
\hline & No & 0.336 & $0.040-2.846$ & 0.317 \\
\hline \multicolumn{2}{|c|}{ Duration of cigarette smoking (Years) } & 1.038 & $0.946,1.139$ & 0.432 \\
\hline \multicolumn{2}{|c|}{ Number of cigars smoked daily } & 1.180 & $0.882,1.579$ & 0.266 \\
\hline \multicolumn{2}{|c|}{ Duration of affliction by SLE(Month) } & 0.999 & $0.997,1.002$ & 0.835 \\
\hline \multicolumn{2}{|c|}{ Body mass index } & $1.392 \#$ & $0.994,1.950$ & 0.054 \\
\hline \multirow{5}{*}{ Body mass index } & $<18.5$ (Underweight) $^{\star}$ & 1.000 & & \\
\hline & 18.5-24.9 (Normal weight) & 4.375 & $0.807-23.714$ & 0.087 \\
\hline & 25.0-29.9 (Overweight) & 7.059 & $1.251-39.841$ & 0.027 \\
\hline & 30.0-34.9 (Class I obesity) & 7.143 & $1.121-45.518$ & 0.037 \\
\hline & 35.0-39.9 (Class II obesity) & 6.667 & $0.809-54.957$ & 0.078 \\
\hline \multirow{2}{*}{ Positive family history of SLE } & Yes & 1.000 & & \\
\hline & No & 0.358 & $0.077-1.663$ & 0.190 \\
\hline
\end{tabular}

Cl: Confidence interval; \#Trend effect; *Reference category.

ond-class obesity were greater by eight, ten and nine times, respectively. The trend test also showed a significant trend for the mean score of SLE DA with increases in the mean score of body mass index (Table 5).

\section{DISCUSSION}

This study aimed to evaluate the relationship of lifestyle with DA among patients with SLE. Findings showed that SLE DA had significant negative relationships with lifestyle and its stress management and spiritual growth dimensions and significant positive relationship with body mass index.

The total mean score of lifestyle was $2.49 \pm 0.30$, indicating poor lifestyle among study participants. A study in Taiwan also showed that patients with SLE had poor lifestyle. ${ }^{24}$ Another study in Iran on patients with chronic diseases other than SLE (including hypertension, cancer, diabetes mellitus, and multiple sclerosis) also showed that the mean score of lifestyle was $2.47 \pm 0.41$ among women and $2.49 \pm 0.37$ among men. ${ }^{34}$

The lowest lifestyle dimensional mean score was related to the physical activity dimension (1.55 \pm 0.60$)$. In line with this finding, a study on patients with SLE in Taiwan showed that the lowest lifestyle dimensional mean score was related to the physical activity dimension..$^{24}$ Another study in Sweden showed that patients with SLE had lower physical activity capacity and less frequent exercise compared with population controls. ${ }^{35}$ Similarly, a study in 
Table 5. The results of multivariate logistic regression analysis to evaluate the relationship of SLEDAI with HPLPII and personal characteristics.

\begin{tabular}{|c|c|c|c|c|}
\hline \multicolumn{2}{|l|}{ Independent variables } & \multirow{2}{*}{$\begin{array}{c}\text { Odds Ratio } \\
0.210\end{array}$} & \multirow{2}{*}{$\frac{\mathbf{9 5 \%} \text { Cl }}{0.068-0.643}$} & \multirow{2}{*}{$\frac{\text { P value }}{0.006}$} \\
\hline \multirow{7}{*}{ Lifestyle } & Total & & & \\
\hline & Physical Activity & 1.919 & $0.874-4.210$ & 0.104 \\
\hline & Stress management & 0.283 & $0.072-1.113$ & 0.071 \\
\hline & Health responsibility & 0.449 & $0.165-1.225$ & 0.118 \\
\hline & Nutrition & 0.878 & $0.321-2.400$ & 0.799 \\
\hline & Spiritual growth & 0.381 & $0.118-1.233$ & 0.107 \\
\hline & Interpersonal relationships & 1.747 & $0.680-4.493$ & 0.247 \\
\hline \multicolumn{2}{|l|}{ Age } & 1.002 & $0.972-1.033$ & 0.907 \\
\hline \multirow{2}{*}{ Gender } & Male* $^{*}$ & & & \\
\hline & Female & 0.215 & $0.042-1.100$ & 0.065 \\
\hline \multirow{3}{*}{ Educational level } & Below diploma* & & & \\
\hline & Diploma & 1.715 & $0.758-3.878$ & 0.195 \\
\hline & University & 1.089 & $0.423-2.802$ & 0.860 \\
\hline \multirow{2}{*}{ Cigarette smoking } & Yes* $^{\star}$ & & & \\
\hline & No & 1.503 & $0.137-16.552$ & 0.739 \\
\hline \multicolumn{2}{|c|}{ Duration of affliction by SLE (Month) } & 0.997 & 0.994-1.001 & 0.209 \\
\hline \multicolumn{2}{|c|}{ Body mass index } & $1.599 \#$ & $1.095-2.335$ & 0.015 \\
\hline \multirow{5}{*}{ Body mass index } & $<18.5$ (Underweight) $^{\star}$ & & & \\
\hline & 18.5-24.9 (Normal weight) & 4.236 & $0.675-26.572$ & 0.123 \\
\hline & 25.0-29.9 (Overweight) & 8.193 & $1.226-54.772$ & 0.030 \\
\hline & 30.0-34.9 (Class I obesity) & 10.432 & $1.371-79.362$ & 0.024 \\
\hline & 35.0-39.9 (Class II obesity) & 9.409 & $0.964-91.811$ & 0.054 \\
\hline \multirow{2}{*}{ Positive family history of SLE } & Yes & & & \\
\hline & No & 0.206 & $0.031-1.375$ & 0.103 \\
\hline
\end{tabular}

Cl: Confidence interval; \#Trend effect; *Reference category.

Italy and a study in Iran showed that most patients with SLE had inadequate physical activity. ${ }^{14} \mathrm{~A}$ study in Iran on patients with chronic conditions also reported that the lowest lifestyle dimensional mean score was related to physical activity with a mean score of $1.95 \pm 0.63$ among men and $1.84 \pm 0.66$ among women. ${ }^{34}$ The low level of physical activity among patients with SLE may be due to SLE-related tissue injuries and psychological problems. ${ }^{35}$ Stress management was the second lowest-scored lifestyle dimension in the present study (score: $1.99 \pm 0.43$ ). Stress management among patients with SLE is of great importance because physical and mental stress can be associated with disease relapse. ${ }^{36}$ However, a study in Iran on patients with chronic conditions showed that the mean score of the stress management dimension of lifestyle was $2.44 \pm 0.46$ among men and $2.42 \pm 0.51$ among women. ${ }^{34}$ Both these mean scores are greater than the mean score of stress management in the present study. This contradiction is attributable to the fact that patients in that study suffered from chronic conditions other than SLE, such as hypertension, cancer, diabetes mellitus, and multiple sclerosis. ${ }^{34}$ Patients with SLE have multisystemic problems and hence, suffer from higher levels of stress.

The mean score of the spiritual growth dimension of lifestyle in the present study was $2.35 \pm 0.50$, indicating poor spiritual growth. A study on patients with chronic conditions in Iran showed that the mean score of spiritual growth was $2.56 \pm 0.49$ among men and $2.54 \pm 0.66$ among women, which are in line with our findings. ${ }^{34}$ Two studies on patients with scleroderma, SLE, and malignant melanoma reported spiritual and mental needs as the most important needs of these patients. ${ }^{37,38}$ The debilitating conditions of patients with SLE in the active 
phase of the disease reduce their ability to perform activities related to spirituality and self-actualization. Similarly, a study in the United States reported the high prevalence of disability in performing valued life activities among patients with SLE. ${ }^{39}$

Our findings showed that the mean score of the interpersonal relationships dimension of lifestyle was $2.77 \pm 0.47$. Similarly, a study on patients with chronic diseases in Iran showed that the mean score of this dimension was $2.64 \pm 0.47$ among men and 2.69 \pm 0.52 among women. ${ }^{34}$ Patients with SLE have concerns over body image and role maintenance which trigger their embarrassment and withdrawal, and negatively affect their social functioning and relationships. ${ }^{40}$ Therefore, development of interpersonal relationships is an effective strategy to prevent disease activation among them, particularly among those with depression and severe SLE. ${ }^{41}$

Study findings showed that the mean score of the nutrition dimension of lifestyle was $2.87 \pm 0.40$. This is in agreement with the findings of a study in Iran on patients with chronic diseases which reported that the mean score of the nutrition dimension among men and women was $2.79 \pm 0.51$ and $2.77 \pm 0.50$, respectively. ${ }^{34}$ Patients with SLE suffer from dyslipidaemias' hypertension, and high value of glucose and hence, need to have a diet moderate in protein and high in vitamins, minerals, antioxidants, and polyunsaturated fatty acids. ${ }^{25,42-44}$ Nonetheless, a study in Iran reported that despite receiving glucocorticoids, only $24 \%$ of patients with SLE consumed a low-salt low-fat diet. ${ }^{14}$

The highest lifestyle dimensional mean score was $3.25 \pm 0.45$ and was related to the health responsibility dimension. Contrarily, a study on patients with SLE in Iran reported that the mean score of health responsibility was $2.49 \pm 0.48$ among men and $2.45 \pm 0.51$ among women. ${ }^{34}$ This contradiction may be due to the fact that patients in the present study referred to the study setting to receive treatment and care-related services based on a predetermined time schedule, and were able to ask their health-related questions of a group of healthcare specialists (including rheumatology specialists, assistants, and residents) who spent a great deal of time on assessing patients' problems and answering their questions. It is noteworthy that patients' health responsibility is greatly affected by quality patient education and effective communication with healthcare providers. ${ }^{45}$

Study findings also showed that $67.5 \%$ of participants had active SLE. A cohort study on 1886 patients with SLE in Sweden showed that almost half of the participants maintained their original DA pattern during the three-year course of the study. ${ }^{46}$ Activation of SLE and subsequent wide use of corticosteroids and immunosuppressants severely damage different body organs which in turn aggravate afflicted patients' conditions, and may finally result in death. ${ }^{47}$
Study findings also revealed a significant negative relationship between health-promoting lifestyle and SLE DA. In line with this finding, a systematic review showed that lifestyle had significant effects on SLE DA and noted that tobacco use increased the risk of skin changes and DA. ${ }^{16}$ A study in Japan also reported a significant relationship between lifestyle and well-being among patients with SLE. ${ }^{25}$ Moreover, our findings indicated that the stress management dimension of lifestyle had significant negative relationship with DA. In agreement with this finding, a study showed that stress can aggravate the clinical symptoms of SLE. ${ }^{48}$ Another study on patients with SLE in India reported that stress had significant relationship with lupus nephritis, so that patients with nephritis had higher levels of stress compared with those without nephritis. ${ }^{45}$ Similarly, a study in Korea showed that patients with higher levels of stress had greater SLE DA. ${ }^{49}$ In addition, we found that the spiritual growth dimension of lifestyle had significant negative relationship with SLE DA. Spirituality/religiosity is an important source of coping among patients with chronic conditions which can significantly reduce their distress. ${ }^{50}$

Study findings showed that around half of the participants were overweight or obese and there was a significant positive relationship between body mass index and SLE DA. Similarly, a former study reported the high prevalence of overweight and obesity among patients with SLE. ${ }^{51}$ A study in the United States also showed that high body mass index was an independent determinant of SLE DA. ${ }^{52}$

\section{Limitations}

Among the limitations of the present study were non-random sampling and data collection through the self-report method. Patients used a wide range of medications, so that it was not possible to measure the relation of type of drug to disease activity. Therefore, it is suggested that in future studies, the relationship between the drugs categorisation used by patients and its relationship with disease activity should be investigated. It is also suggested that other underlying diseases of patients and organ involvement be considered in future.

\section{CONCLUSION}

This study suggests that patients with SLE have poor lifestyle, most of them have active disease, and their DA has significant negative relationship with lifestyle and significant positive relationship with body mass index. Therefore, interventions are needed to promote lifestyle among these patients and thereby, reduce their DA. Improving physicians' and nurses' knowledge about SLE and lifestyle modification can also be an effective strategy for promoting health-related outcomes and reducing DA among patients with SLE. Other important strategies with potential effects on DA among these patients are 
interventions for promoting weight management, stress management, and spiritual growth.

\section{AUTHOR CONTRIBUTIONS}

LS conceived the study, participated in its design, led its coordination, and helped to draft the manuscript. STF helped design of the study, developed the methods, and interpreted the results. $\mathrm{MH}$ contributed to the interpretation of the results and helped draft the manuscript. SJ conceived the study, participated in design of the study, wrote the draft of the manuscript.

\section{ACKNOWLEDGEMENTS}

Much gratitude to the Nursing and Midwifery Care Research Centre, School of Nursing and Midwifery, and Rheumatology Research Centre related to Tehran University of Medical Sciences for their generous assistance in supporting this research. We would like to thank all patients who participated in this study.

\section{CONFLICT OF INTEREST}

The authors declare no conflict of interest.

\section{FUNDING}

This study is a part of research that funded and supported by Nursing and Midwifery Care Research Centre and School of Nursing \& Midwifery, Tehran University of Medical sciences (TUMS); Grant no. 97-03-99-40546.

\section{ETHICAL APPROVAL}

The Institutional Review Board of School of Nursing and Midwifery \& Rehabilitation - Tehran University of Medical Sciences approved this study (IR.TUMS.FNM. REC.1397.207). Participants were provided with information about the study aim, and then, written informed consent was obtained from each of them.

\section{REFERENCES}

1. Ferenkeh-Koroma A. Systemic lupus erythematosus: nurse and patient education. Nurs Stand 2012;26:49-57.

2. Yeoh S-A, Dias SS, Isenberg DA. Advances in systemic lupus erythematosus. Medicine 2018;46:84-92.

3. Gatto M, Zen M, Ghirardello A, Bettio S, Bassi N, laccarino L, et al. Emerging and critical issues in the pathogenesis of lupus. Autoimmun Rev 2013;12:523-36.

4. Akbarian M, Faezi ST, Gharibdoost F, Shahram F, Nadji A, Jamshidi AR, et al. Systemic lupus erythematosus in Iran: a study of 2280 patients over 33 years. Int J Rheum Dis 2010;13:374-9.

5. Akbarian M, Faezi ST, Gharibdoost F, Shahram F, Nadji A, Jamshidi AR, et al. The epidemiology of systemic lupus erythematosus in Iran: a survey on 2143 cases. Tehran Univ Med J 2010; 68(5):3005.

6. Özel F, Argon G. The effects of fatigue and pain on daily life activities in systemic lupus erythematosus. Agri 2015;27(4):181-9.

7. Mazhari Azad F, Abedi Heidar A, Naji Seyed A. [Experience of living with Systemic Lupus Erythematosus: A phenomenological study]. Med Surg Nurs J 2015;4:1-9. (In Persian)

8. 8. Hosseini N, Bonakdar ZS, Gholamrezaei A, Fatemi A, Karimzadeh $\mathrm{H}$. [Evaluating the Validity and Reliability of Persian Version of Lupus Quality of Life (LupusQol) Questionnaire in Iranian Patients].
J Isfahan Med Sch 2014;31:1836-47. [In Persian]

9. Sadat Shakeri H, Jokar M, Jafarzade F, Noorshafiee S, Akhlaghi $\mathrm{S}$. [Evaluation the incidence of infections in patients with systemic lupus erythematous.] JNKUMS 2013;5:579-83. [In Persian]

10. Lehman T, Nuruzzaman F, Taber S. Chapter 8 - Systemic Lupus Erythematosus: Etiology, Pathogenesis, Clinical Manifestations, and Management. In: Cimaz R, Lehman T, editors. Handbook of Systemic Autoimmune Diseases. 11: Elsevier. 2016;173-89.

11. Lee YH, Choi SJ, Ji JD, Song GG. Overall and cause-specific mortality in systemic lupus erythematosus: an updated meta-analysis. Lupus 2016;25:727-34

12. Gordon C, Amissah-Arthur MB, Gayed M, Brown S, Bruce IN, D'Cruz D, et al. The British Society for Rheumatology guideline for the management of systemic lupus erythematosus in adults. Rheumatology 2017; 57:e1-e45.

13. Mikdashi J, Nived O. Measuring disease activity in adults with systemic lupus erythematosus: the challenges of administrative burden and responsiveness to patient concerns in clinical research. Arthritis Res Ther 2015;17:183.

14. Hatef-Fard MR, Khodabandeh M, Sahebari M, Ghayour-Mobarhan M, Rezaieyazdi Z. Metabolic syndrome in lupus patients in northeast of Iran, and their lifestyle habits. Caspian J Intern Med 2016;7:195-200.

15. Pettersson S, Boström C, Eriksson K, Svenungsson E, Gunnarsson I, Henriksson EW. Lifestyle habits and fatigue among people with systemic lupus erythematosus and matched population controls. Lupus 2015;24:955-65.

16. Rodríguez Huerta MD, Trujillo-Martín MM, Rúa-Figueroa Í, Cuellar-Pompa L, Quirós-López R, Serrano-Aguilar P. Healthy lifestyle habits for patients with systemic lupus erythematosus: A systemic review. Semin Arthritis Rheum 2016;45:463-70.

17. Mohammadi Zeidi I, Pakpour Hajiagha A, Mohammadi Zeidi B. [Reliability and Validity of Persian Version of the Health-Promoting Lifestyle Profile.] J Mazand Univ Med Sci 2012;21:102-13. [In Persian]

18. Mora Ripoll R. Lifestyle medicine: The importance of considering all the causes of disease. Rev Psiquiatr Salud Ment 2012;5:48-52.

19. Egger GJ, Binns AF, Rossner SR. The emergence of "lifestyle medicine" as a structured approach for management of chronic disease. Med J Aust 2009;190:143-5.

20. Dua AB, Touma Z, Toloza S, Jolly M. Top 10 Recent Developments in Health-Related Quality of Life in Patients with Systemic Lupus Erythematosus. Curr Rheumatol Rep 2013;15:380.

21. Li XL, Liu LS, Zhang YM, Wu HL, Huang F. Study of quality of Life and nursing-measures improvement in SLE patients: 0456. Int $J$ Rheum Dis 2010;13:225.

22. Nuttall A, Isenberg DA. Assessment of disease activity, damage and quality of life in systemic lupus erythematosus: new aspects. Best Pract Res Clin Rheumatol 2013;27:309-18.

23. Yilmaz-Oner S, Oner C, Dogukan FM, Moses TF, Demir K, Tekayev $N$, et al. Health-related quality of life assessed by LupusQoL questionnaire and SF-36 in Turkish patients with systemic lupus erythematosus. Clin Rheumatol 2016;35:617-22.

24. Huang H-C, Chou C-T, Lin K-C, Chao Y-FC. The relationships between disability level, health-promoting lifestyle, and quality of life in outpatients with systemic lupus erythematosus. J Nurs Res 2007;15:21-32.

25. Behiry ME, Salem MR, Alnaggar AR. Assessment of nutritional status and disease activity level in Systemic Lupus Erythematosus patients at a tertiary care hospital. Rev Colomb Reumatol 2019;26(2):97-104.

26. Khan A, Shah MH, Nauman M, Hakim I, Shahid G, Niaz P, et al. Clinical manifestations of patients with Systemic Lupus Erythematosus (SLE) in Khyber Pakhtunkhwa. J Pak Med Assoc 2017;67:1180-5.

27. Fatemi A, Matinfar M, Sayedbonakdar Z, Maracy M, Karimzadeh $\mathrm{H}$, Saber M, et al. Outcome of adult onset systemic lupus erythematosus in Iran. Lupus 2014;23:1211-6.

28. Rastegar M, Zendehtalab H, Yavari M, Mazlom S. Health-promoting lifestyle and its related factors among health volunteers Mashhad in 2015. JMS 2015;3:55-48. 
29. Lolokote S, Hidru TH, Li X. Do socio-cultural factors influence college students' self-rated health status and health-promoting lifestyles? A cross-sectional multicenter study in Dalian, China. BMC Public Health 2017;17:478.

30. Walker SN, Sechrist KR, Pender NJ. Health Promotion Model Instruments to Measure Health Promoting Lifestyle: Health-Promoting Lifestyle Profile [HPLP II] (Adult Version). 1995. Available at: https://deepblue.lib.umich.edu/handle/2027.42/85349. Access date: 2019.

31. Pinar R, Celik R, Bahcecik N. Reliability and construct validity of the Health-Promoting Lifestyle Profile II in an adult Turkish population. Nurs Res 2009;58:184-93.

32. Gladman DD, Ibañez D, Urowitz MB. Systemic lupus erythematosus disease activity index 2000. J Rheumatol 2002;29:288-91.

33. Zhang X, Tian Y, Li J, Zhao X. Effect of targeted nursing applied to SLE patients. Exp Ther Med 2016;11:2209-12.

34. Siboni F, Khatooni M, Atashi V. Health-promoting lifestyle practices among patients with chronic diseases and its related factors. $J$ Health Soc Behav 2018;1:67-73.

35. Eriksson K, Svenungsson E, Karreskog H, Gunnarsson I, Gustafsson J, Möller S, et al. Physical activity in patients with systemic lupus erythematosus and matched controls. Scandinavian Journal of Rheumatology. Scand J Rheumatol 2012;41:290-7.

36. Roussou E, lacovou C, Weerakoon A, Ahmed K. Stress as a trigger of disease flares in SLE. Rheumatology International. Rheumatol Int 2013; 33:1367-70.

37. Moses N, Wiggers J, Nicholas C, Cockburn J. Prevalence and correlates of perceived unmet needs of people with systemic lupus erythematosus. Patient Education and Counseling. Patient Educ Couns 2005;57:30-8.

38. Pilch M, Scharf SN, Lukanz M, Wutte NJ, Fink-Puches R, Glawischnig-Goschnik M, et al. Spiritual well-being and coping in scleroderma, lupus erythematosus, and melanoma. J Dtsch Dermatol Ges 2016;14:717-28.

39. Katz P, Morris A, Trupin L, Yazdany J, Yelin E. Disability in valued life activities among individuals with systemic lupus erythematosus. Arthritis Rheum 2008;59:465-73.

40. Rutter S, Kiemle G. Exploring the social and interpersonal experiences of South Asian women with a diagnosis of Systemic Lupus Erythematosus. Psychol Health 2015;30:318-35.

41. Drenkard C, Bao G, Lewis TT, Pobiner B, Priest J, Lim SS. Physician-patient interactions in African American patients with systemic lupus erythematosus: Demographic characteristics and relationship with disease activity and depression. Semin Arthritis Rheum 2019;48:669-77.

42. Aparicio-Soto M, Sánchez-Hidalgo M, Alarcón-de-la-Lastra C. An update on diet and nutritional factors in systemic lupus erythematosus management. Nutr Res Rev 2017;30:118-37.

43. Klack K, Bonfa E, Borba Neto EF. Diet and nutritional aspects in systemic lupus erythematosus. Rev Bras Reumatol 2012;52:384408.

44. Charoenwoodhipong P, Harlow SD, Marder W, Hassett AL, McCune WJ, Gordon C, et al. Dietary omega polyunsaturated fatty acid intake and patient-reported outcomes in systemic lupus erythematosus: The Michigan Lupus Epidemiology \& Surveillance (MILES) Program. Arthritis Care Res (Hoboken) 2020;72:874-81.

45. Kimberly C. Patient responsibility: a comparative review of administrator and patient perspectives. Dissertation, University of Pittsburgh. 2016.

46. Györi N, Giannakou I, Chatzidionysiou K, Magder L, van Vollenhoven RF, Petri M. Disease activity patterns over time in patients with SLE: analysis of the Hopkins Lupus Cohort. Lupus Sci Med 2017;8;4:e000192.

47. Zen M, Bassi N, Nalotto L, Canova M, Bettio S, Gatto M, et al. Disease activity patterns in a monocentric cohort of SLE patients: a seven-year follow-up study. Clin Exp Rheumatol 2012;30:856-63.

48. Williams EM, Penfield M, Kamen D, Oates JC. An Intervention to Reduce Psychosocial and Biological Indicators of Stress in African American Lupus Patients: The Balancing Lupus Experiences with
Stress Strategies Study. Open J Prev Med 2014;4(1):22-31.

49. Jung J-Y, Nam J-Y, Kim H-A, Suh C-H. Elevated Salivary Alpha-Amylase Level, Association Between Depression and Disease Activity, and Stress as a Predictor of Disease Flare in Systemic Lupus Erythematosus: A Prospective Case-Control Study. Medicine (Baltimore) 2015;94:e1184.

50. Büssing A, Koenig HG. Spiritual needs of patients with chronic diseases. Religions 2010;1(1):18-27.

51. Katz P, Julian L, Tonner MC, Yazdany J, Trupin L, Yelin E, et al. Physical activity, obesity, and cognitive impairment among women with systemic lupus erythematosus. Arthritis Care Res (Hoboken) 2012;64:502-10.

52. Teh P, Zakhary B, Sandhu VK. The impact of obesity on SLE disease activity: findings from the Southern California Lupus Registry (SCOLR). Clin Rheumatol 2019;38:597-600. 